\title{
Study of Injection of Helium Into Supersonic Air Flow Using Rayleigh Scattering
}

Richard G. Seasholtz and Alvin E. Buggele

Lewis Research Center

Cleveland, Ohio

Prepared for the

35th Aerospace Sciences Meeting \& Exhibit

sponsored by the American Institute of Aeronautics and Astronautics

Reno, Nevada, January 6-10, 1997

National Aeronautics and

Space Administration 


\title{
STUDY OF INJECTION OF HELIUM INTO SUPERSONIC AIR FLOW USING RAYLEIGH SCATTERING
}

\author{
R. G. Seasholtz* and A. E. Buggele ${ }^{\dagger}$ \\ NASA Lewis Research Center \\ Cleveland, $\mathrm{OH} 44135$
}

\begin{abstract}
A study of the transverse injection of helium into a Mach 3 crossflow is presented. Filtered Rayleigh scattering is used to measure penetration and helium mole fraction in the mixing segion. The method is based on planar molecular Rayleigh scattering using an injection-seeded, frequency-doubled Nd:YAG pulsed laser and a cooled CCD camera. The scattered light is filtered with an iodine absorption cell so suppress stray laser light. Preliminary data are presented for helium mole fraction and penetration. Wow visualization images obtained with a shadowgraph and wall static pressure data in the vicinity of the injection are also presented.
\end{abstract}

\section{Introduction}

The quantitative characterization of gas injection into supersonic flow is important for improving the mixing efficiency of new supersonic combustor designs and for LOX (liquid oxygen) Augmented Nuclear Thermal Rocket (LANTR) concepts'. The goal of the test program is to investigate the injection, penetration, and mixing dynamics of different injector designs. This paper reports the initial work in this program, where planar filtered Rayleigh scattering was used to measure mole fraction and penetration of helium injected transversely from a sonic nozzle into a supersonic air flow. The test injectors were mounted in the NASA Lewis 3.81 inch by 10.0 inch supersonic wind tunnel. The initial test configuration used 0.25 inch diameter sonic injection ports mounted in the tunnel roof and/or floor downstream of the tunnel nozzle exit. The free stream tunnel Mach number was nominally 3.0. Shadowgraph flow visualization images and static pressure measurements in the vicinity of the injectors are also presented.

Previous mixing studies by other researchers have

\footnotetext{
"Senior Research Engineer, Member AlAA

${ }^{\dagger}$ Senior Research Operations Engineer, Senior Member AIAA.
}

used probes ${ }^{2,3}$ or Mie scattering ${ }^{4,5}$ to map the flow. A 3D visualization study was come using Mie scattering

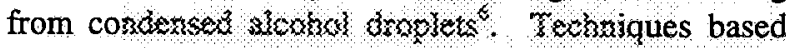
on Mie seattering from ratricies sestest into the now have potential problems caused by tz̧s inabsility of the particles to follow large flow accelerations and because particles do not diffuse like gas molecules? ${ }^{7}$. Laser induced fluorescence tas been used in a flow seeded

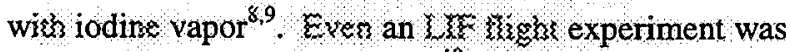
conducted using iodine seeding ${ }^{2}$. However, because of the corrosive nature of iodine, this approach is not suitable for many facilities. Planar LIF has been used for both nonzeacking (seeded with nitric oxide) and reacting flows (using $O K X$ formed by combustion) ${ }^{11}$. Schlieren flow visualization has been used by several researchers ${ }^{12,13}$. A recent example of the use of Schlieren is the study of low-angled supersonic gaseous injection into a supersonic freestream ${ }^{14}$. Analytical studies of the penetration of gaseous jets into supersonic flow have also been conducted ${ }^{35}$. An aspirating hotfilm concentration probe has been used to measure helium concentration in a study of mixing at high supersonic speeds ${ }^{16}$.

Rayleigh scattering has been used by various researchers to make quantitative point and planar measurement of concentration in turbslent flows ${ }^{17,18}$. Point measurements have been made in a small burner with frequency response in excess of $10 \mathrm{kHz}^{19}$. Mixture fractions have been measured in a reacting flow using a copper-vapor laser ${ }^{20}$. Temperature and mixture fraction have been obtained in a turbulent diffusion flame ${ }^{21}$. Two-dimensional concentration measurements have been reported for turbulent flames ${ }^{22}$, and fuel-air concentrations were measured in a propane-air mixture ${ }^{23}$.

The objective of our work is to obtain quantitative measurements of the mole fraction of helium injected from one or more injectors into supersonic air flow. Molecular Rayleigh scattering was chosen to make these measurements because of the following reasons: (1) no seeding of the flow is required; (2) the laser system is relatively simple compared to some other techniques; and (3) quantitative mixing data, including molecular diffusion effects, can be obtained in a relatively straightforward manner. 
The well-known difficulties in applying Rayleigh scattering are stray laser light and Mie scattering from particles in the flow. Submicron filters in the air supply should reduce the particle loading to an acceptable level for Rayleigh scattering measurements. The problem of stray laser light is particularly severe in this application because of the close proximity of the measurement region to the location where the laser beam enters and exits the tunnel sidewalls. We selected the technique of filtered Rayleigh scattering ${ }^{24,25}$ to suppress this stray light. However, complete suppression was not achieved. The intensity of the stray light was still about an order of magnitude greater than the Rayleigh scattering intensity. A data processing technique using the difference between images with and without injection was applied, which results in cancellation of the stray background light. However, even though the average value of the background is eliminated, the noise component remains, which significantly degrades the accuracy of the mole fraction measurement.

A pulsed laser was used because it offers two advantages compared to a $\mathrm{CW}$ source. One is that an instantaneous view of the mixing process can be obtained if images can be recorded with a single laser pulse. The second advantage is that if a small number of particles are present in the flow, their images can be easily identified and removed with an image processing algorithm. Images obtained with a $\mathrm{CW}$ laser, on the other hand, will include the integrated effect of all particles passing through the laser sheet during the exposure. In this preliminary work, however, we only took 10-shot average data. Single-shot images were not obtained because of the low signal-to-noise ratio resulting from the large amount of stray laser light.

\section{Ravleigh scattering}

\section{Theory}

Molecular Rayleigh scattering is proportional to both the gas density and the Rayleigh scattering cross section. For a single species gas of volume $V$ with number density $n$ illuminated by a laser beam with wavelength $\lambda$ and intensity $I_{o}$, the power scattered into solid angle $d \Omega$ is

$$
P_{s}=I_{o} n V\left(\frac{\mathrm{d} \sigma}{\mathrm{d} \Omega}\right) \sin ^{2} \chi \mathrm{d} \Omega
$$

where $d \sigma / d \Omega$ is the differential scattering cross section and $\chi$ is the angle between the electric field vector of the (linearly polarized) incident light and the direction of the scattered light.

The shape of the Rayleigh spectrum is, in general, a function of the scattering angle and the gas density.
For the low density flows in this work, however, the spectrum has a simple Gaussian shape

$$
S_{R}(f) d f=\frac{1}{\sqrt{\pi} a K} \exp \left\{-\left[\frac{2 \pi\left(f-f_{o}\right)-\mathbf{K} \cdot \mathbf{u}}{a K}\right]^{2}\right\}
$$

where $\mathbf{K}=\mathbf{k}_{\mathrm{s}}-\mathbf{k}_{\mathrm{o}}$ is the interaction wave vector with magnitude (wave number) $K=(4 / \lambda) \sin \left(\theta_{s} / 2\right), \mathbf{k}_{\mathrm{o}}$ and $\mathbf{k}_{\mathrm{s}}$ are the wave vectors of the incident and scattered light, $\theta_{\mathrm{s}}$ is the scattering angle, $a=(2 \mathrm{KT} / \mathrm{m})^{1 / 2}$ is the most probable molecular speed (with $\kappa$ being Boltzmann's constant, $m$ the molecular mass, $T$ the gas ermeratare), and $\mathbf{u}$ is the mean gas velocity. Note that the spectrum is only sensitive to one component of the thas velocity (the component along $\mathbf{K}$ ).

Consider a laser sheet of energy $E_{\mathrm{o}}$ that uniformly illuminates a region in the orject plane. The height of the sheet is assumed to correspond to the heighn viewed by $N_{R}$ rows of pixels (measured perpendicular to the beam propagation direction), and the length viewed by each pixel (along the beam propagation direction) is $L_{x}$. If the optical system has solid collection angle $\Omega$ and includes an iodine absorption cell, the expected number of detected photons for an optical for the $q^{\text {th }}$ pixel can be written

$$
\begin{aligned}
& \left\langle N_{D q}\right\rangle=\iint_{\Delta A}^{\infty}\left[\left\langle N_{R q}\right\rangle S_{R}(f)\right. \\
& \left.+\left\langle N_{W_{q}}\right\rangle \delta\left(f-f_{o}\right)\right] I_{F}(f) \mathrm{d} f \mathrm{~d} A+B_{q}
\end{aligned}
$$

where

$$
\left\langle N_{R q}\right\rangle=\frac{\varepsilon E_{o} n L_{x} \lambda \Omega}{N_{R} h c}\left(\frac{\mathrm{d} \sigma}{\mathrm{d} \Omega}\right) \sin ^{2} \chi
$$

is the number of photons scattered (Rayleigh scattering) that would be detected by the $q^{\text {th }}$ pixel if the iodine absorption cell were not present. Similarly, $\left\langle N_{W q}\right\rangle$ is the number of photons due to laser light scattered from windows and walls at the laser frequency $f_{o}=c / \lambda_{0}$. Broadband background light, detector dark current, and readout noise are represented by $B_{q}$. Although scattering from particles is not included, it could be easily incorporated. The overall detection efficiency $\varepsilon$ includes detector quantum efficiency and system losses. $I(f)$ represents the transmission function of the iodine absorption filter.

\section{Iodine absorption cell}

The iodine absorption spectrum is calculated using the model developed by Forkey ${ }^{26}$. The effect of an iodine absorption cell on a Gaussian Rayleigh scattering spectrum is illustrated in figure 1 . The cell length is $200 \mathrm{~mm}$, the iodine vapor pressure is 0.46 torr, and the cell temperature is $328 \mathrm{~K}$. The scattering angle is $135^{\circ}$. For these iodine cell parameters, the attenuation of light 
at the maximum absorption (at $18788.44 \mathrm{~cm}^{-1}$ ) is predicted to be about $10^{6}: 1$. However, the observed attenuation is not this large. This has been observed by other researches using injection seeded Nd:YAG lasers $^{26,27}$. The probable explanation is that the laser is lasing in a mode other than that matched to the injection seed laser.

The expected signal level can be calculated for the optical setup used for this work (described below in the optical setup section). The scattering angle was $\$ 35^{\circ}$. The observed magnification was such that $1 \mathrm{~mm}$ in the flow corresponded to 10.0 pixels on the CCD, so $N_{R}=$ 384 , and $L_{x}=0.141 \mathrm{~mm}$ (including the effect of the oblique viewing angle). Using a total pressure of 42 psia a total temperature of $293 \mathrm{~K}$ and an effective $\mathrm{f}$ number for light collection of $f / 10$, gives about 700 detected photons per pulse. For $\hat{\alpha} \leqslant 0$ pulss exposure, the total count would be 7000 . As shown on figure 1 , filtering by the iodine cell reduces this by about $25 \%$, so the expected photoelectron count/pixel is about 5000 .

\section{Mole fraction measurement}

For a binary gas mixture of air and helium the total Rayleigh scattered is the sum of the cross sections of its constituents weighted by their mole fractions. The measured light energy on the $i^{\text {th }}$ pixel can be written

$$
I_{m i}=A_{i}\left(n_{H e, i} \sigma_{H e}+n_{A i r, i} \sigma_{A i r}\right) I_{o}+B_{i} I_{o}
$$

where $n_{H e, i}$ and $n_{A i r, i}$ are the number densities of helium and air in the region viewed by the $i^{\text {th }}$ pixel; $A_{i}$ is a proportionality constant that is a function of the distribution of laser intensity in the image and of the collection efficiency; $B_{i}$ is proportional to the non Rayleigh scattered light (i.e., stray laser light); $\sigma_{A i r}$ and $\sigma_{H e}$ are the differential Rayleigh scattering cross sections (written in a simpler form than the notation used in equations 1 and 4); and $I_{o}$ is a measure of the laser energy. The constants $A_{i}$ and $B_{i}$ can be determined by making two measurements (denoted measurements 1 and 2) at different known values of $n_{\text {Air }}$ with no helium in the flow. For air densities $n_{\text {Airl }}$ and $n_{\text {Air } 2}$ we have

$$
\begin{aligned}
& A_{i}=\frac{I_{m 2, i} / I_{o}-I_{m 1, i} / I_{o}}{\left(n_{A i r 2}-n_{A i r l}\right) \sigma_{A i r}} \\
& B_{i}=\frac{I_{m 1, i}}{I_{o}}-A_{i} n_{\text {Air } 1} \sigma_{A i r}
\end{aligned}
$$

Once the calibration constants $A_{i}$ and $B_{i}$ have been determined, two additional measurements, one without injection (denoted measurement 3 ), and one with injection (denoted measurement 4) can be used to obtain mole fraction if we assume that the total number density of the helium-air mixture is equal to the number density of the flow without helium injection. This assumption is equivalent to assuming that both the static pressure and the static temperature are unchanged. This clearly is not valid in the close vicinity of the injection port where the injected gas is rapidly expanding. However, our measurements were taken as least four nozzle diameters downstream from the injector, where surface pressure measurements indicated that the static pressure has returned to the upstream tunnel pressure.

The helium mole fraction in an air-helium mixture is defined as

$$
F_{H e}=\frac{n_{H e}}{n_{A i r}+n_{H e}}=1-\frac{n_{A i r}}{n_{T}}
$$

where $n_{T}=n_{A i r}+n_{H e}$ is the total molecular number density. Measurements 3 (no injestion) and 4 (witk injection) then give the helium mole fraction for $x_{i k f}$ pixel

$$
F_{H e, i}=\frac{I_{m 3, i} / I_{o}-\zeta_{m 4, i} / I_{o}}{I_{m 3, i} / I_{o}-B_{i}} \frac{1}{1-\sigma_{H e} / \sigma_{A i r}}
$$

Because the mole fraction is proportional to the difference of the images, any changes in the jutersity

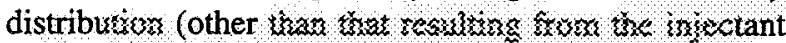
flow) will result in retatively large emors. For example, small changes in the location of use laser saams can cause rolutively large changes in the intensity and distribution of the stray kight. This cart 30 causod. for exampie, by comperatuza changes $k \pi$ the opriss that cause the beam prokise to change. Thuss it is smoortant that the set of four images be taken within a sisor time interval. It is asso convenzen to use kne flow without injection for the calibration as well as the flow condition 3 . This allows the mole fraction measurement to be obtained with only three images. In any case, the images for injection and no injection should be taken as close in time as is feasible.

With the iodine absorption cell, the calibration data should be obtained with flow conditions having the same velocity and temperature. This ensures that the filtered kayieigh scattering will have the same fraction of the total Rayleigh scattered light. In operation, this can be done by taking the calibration data at different tunnel total pressures.

\section{Uncertainty Analysis}

In this section we estimate the uncertainty in the helium mole fraction measurement due to photon statistical noise. This is a fundamental lower bound on the uncertainty. In practice, other factors will result in a larger uncertainty. Assuming that the measurements are uncorrelated and that the variance in the photodestron counts/pixel is equal to the expected count (Poisson statistics), we can readily calculate the uncertainty in the helium mole fraction for each pixel. 


$$
\sigma_{F_{H e}}=F_{H e}\left[\frac{I_{m 3}+I_{m 4}+2 \sigma_{R}^{2}}{F_{H e}^{2} I_{R S 3}^{2}}+\frac{I_{m 2}+I_{m 1}+2 \sigma_{R}^{2}}{\left(I_{R S 2}-I_{R S 1}\right)^{2}}\right]^{1 / 2}
$$

The intensities in this expression are in terms of photoelectrons, and $\sigma_{R}$ represents the CCD read noise. The terms in the denominator represent differences in the Rayleigh scattering signals if the background is equal for the four exposures. Figure 2 shows the helium mole fraction uncertainty for several values of background due to stray laser light for Rayleigh scattering intensities corresponding to our tests. Note that the minimum uncertainty (for no stray light) is about 0.05 . For stray light levels observed in this study, however, the uncertainty is much larger. As shown below, a typical value of stray light intensity is about 25,000 photoelectrons (note that the actual photoelectron count is about a factor of 5 larger than the readout count from the CCD camera).

\section{Wind tunnel}

\section{Experiment}

The continuous flow tunnel (fig. 3) has a 3.81 inch (width) by 10.0 inch (height) supersonic test section about 40 inches in length. The inlet pressure was nominally 42.5 psia with an exit pressure less than 1.5 psia at maximum mass flow conditions tested. Depending on services available, inlet pressure could reach nearly 50 psia with the Mach 3 nozzle blocks. The tunnel inlet air was filtered to remove particulates with diameters larger than $0.2 \mu \mathrm{m}$. The injectant flow, however, was not filtered. The boundary layer was controlled with compartmentalized bleed modules located in the side walls before the nozzle contraction and in the roof and floor downstream of the helium injectors. Boundary layer thickness without injection ranged from 0.4 inch to 0.5 inch for the region 4 to 30 nozzle diameters downstream of the injector. The 0.25 inch diameter helium injection nozzles are mounted in the tunnel floor and roof 1.85 inches downstream of the tunnel nozzle exit plane. The injection nozzles have a constant diameter with an L/D of 1. Full roof-to-floor optical access is provided by glass windows mounted in the tunnel side walls. The helium injection nozzles are operated at approximately the same total pressure as the tunnel inlet. The helium supply consisted of four standard 220 scf gas cylinders. Injection could be made, either individually or simultaneously, through the floor and roof nozzles. This arrangement provided about $90 \mathrm{sec}$ of helium flow through a single injector. Operation with helium flow through multiple injectors decreased this time accordingly. A large number of static pressure taps were placed in the roof (55 taps) and floor (57 taps) injector plates as shown on figure 3 .

\section{Rayleigh scattering optical setup}

The optical setup is shown in figure 4 . The beam from the injection-seeded, frequency-doubled Nd:YAG laser $(0.7 \mathrm{~J}, 532 \mathrm{~nm}, 10 \mathrm{~Hz}$ pulse rate, $8 \mathrm{~ns}$ pulse duration) was formed into a sheet about $40 \mathrm{~mm}$ high using a combination of spherical and cylindrical optics. The laser beam is passed through the 47 inch long, 1.2 inch thick, full roof-to-floor windows. The windows are plate glass, with a relatively large number of included bubbles. These windows have been in use for a number of years, and the inner surfaces of the windows have been abraded by particle impacts. These pors quaisty surfaces resulted in a large amount of laser scattering.

Light is collected at $45^{\circ}$ to the beam direction, passed through the iodine cell, and is imaged onto the liquid nitrogen cooled $\mathrm{CCD}$ array $(1752 \times 532$ pixels, $70 \%$ quantum efficiency) with a $85 \mathrm{~mm}$ focal length, $\mathrm{f} / 1.4$ lens. This resulted in a pixel viewing a region on the laser sheet $0.10 \mathrm{~mm}$ high by $0.14 \mathrm{~mm}$ wide (the width being larger because of the oblique viewing angle). This oblique viewing causes keystone distortion and defocusing. The limited depth of focus caused a significant blurring of particle images and made it difficult to effectively remove them. In addition, this caused the spatial resolution of the measurement to be only about 1 or $2 \mathrm{~mm}$. To correct this, the lens and CCD should be aligned in accordance with the Scheimpflug condition ${ }^{28}$, which was not done in this study.

Extensive baffling was incorporated to minimize the amount of stray laser light that reached the CCD camera. Only a fraction of the total CCD array was used (about $350 \times 500$ pixels), which reduced the time required to transfer the $C C D$ image to the computer to about 7 seconds. Because of the expected small number of Rayleigh scattering photoelectron counts/pixel, all data were taken using 10-shot exposures. The laser and optics are mounted on a remotely controlled 3-axis positioning system.

\section{Shadowgraph flow visualization}

A shadowgraph system was also used to visualize the flow. The double pass shadowgraph system used 30 inch diameter concave surface mirror and a 16 inch by 24 inch front surface flat mirror. The normal field of view recorded by the visualization system was the full tunnel height of 10 inches high by over 17 inches long. Two techniques were used to record shadowgraph images. The first technique used a continuous light

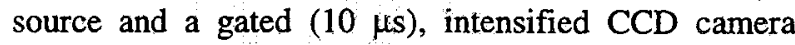
with an RS170 output. These images were recorded on a VCR and provided a continuous visualization of the 
flow. A computer frame-grabber could also be used to capture these images. The second technique used a pulsed light source with the image recorded with a 35mm camera. These images were of higher quality than the VCR recorded images. Figure 5 shows images obtained with the 35-mm camera. Because the Rayleigh scattering optics obscured the field of view of the shadowgraph, simultaneous Rayleigh scattering data and shadowgraphs could not be obtained.

\section{Rayleigh scattering}

\section{Experimental results}

Two sets of Rayleigh scattering data were taken. The first set (denoted RDG 2040) was taken approximately 4 nozzle diameters (1.075 inches) downstream of the leading edge of the 0.25 inch diameter injector mounted in the tunnel roof. The tunnel was operating at Mach 3 with a total pressure of 42.3 psia; the gaseous helium injection total pressure was 40.3 psia. Typical raw images obtained with the Rayleigh scattering system are shown in figure 6 . Note the particle images on figures $6 \mathrm{~b}$ and $6 \mathrm{c}$ (with helium flow). These are apparently in the unfiltered injectant flow. The receiving optics for this set of measurements incorporated a mask with a relatively large aperture, which did not block the view of the tunnel roof. The average value of the recorded intensity in this image is about 25,000 photoelectron counts. Since the expected Rayleigh scattering intensity for the flow without injection is about 5000 photoelectrons/pixel, we expect an uncertainty (based on fig. 2) of about 0.1 to 0.2 depending on the mole fraction. Figure 7 shows mole fraction data calculated using the scheme described above. Calibration for these images was based on flow at tunnel total pressures of 30.3 and 42.3 psia (6.4 and 9.3 pps mass flow rates). The part of the image with the "salt-and-pepper" pattern is where the Rayleigh scattering signal was too weak to obtain a calibration. Also, because these images were obtained by subtracting flow images with injection from flow images without injection, white particle images correspond to particles in the flow without injection, while black particle images correspond to particles in the flow with injection.

The momentum flux ratio, defined as

$$
J=\frac{\gamma_{H e} p_{H e} M_{H e}^{2}}{\gamma_{A i r} p_{A i r} M_{A i r}^{2}}
$$

is a parameter commonly used to characterize penetration of a jet into crossflow. For our tests $J=$ 2.25. Here, the helium pressure and Mach number are the values at the injector exit, and the air values are those of the tunnel free stream.
A second series of test runs (denoted RDG 2110 2118) was made using the 0.25 inch diameter injector mounted in the tunnel floor. The tunnel operating conditions were approximately equal to the test conditions of RDG 2040. For this test, data were obtained at a number of downstream locations, but the calibration data were not taken because of limited run time. (The calibration requires that the tunnel operating condition be changed.) A mask with a smaller aperture was employed in this test in an attempt to reduce the amousu of stray laser light reaching the CCD. As a result, the region near the tunnel floor was not visible in the recotaed images. (This smaller mask, however, did not significantly reduce the amount of detected stray light.) Figures 8 shows the irma data obtained by subtracting images with helium injection from images without injection. Kosese provide qualitative information on the mixing and information on the penetration of the helium into tunnel flow.

Shadowgraph images were obtained at the same flow conditions as the Rayleigh scattering images, but

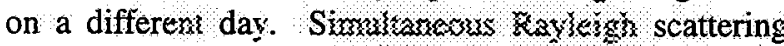
and shadowgraph images could not be obtained with this setup because kayleigh scattering optics obscured the field of view of the shadowgraph. Figure $5 b$ is a shadowgraph kaken under the same flow conditions as the Rayerig seatering data shown in figure 7. The helium plume can be seen at the bottom of the shadowgraph. Note that the injector was located upstream of the leading edge of the window. A 4.5 inch long pitot probe located 2 inches above the tunnel centerline is also visible in the shadowgraph along with the bow shock caused by the injected helium jet. The edge of the helium plume was difficult to accurately determine from the single-shot shadowgraphs because of the dynamic, turbulent nature of the interface between the helium plume and the tunnel flow.

The helium penetration taken from the Rayleigh scattering images and from two shadowgraphs are shown in figure 9 . The penetration obtained from the Rayleigh scattering images was determined by visually selecting the maximum distance discernible from the images shown on figures 7 and 8 . We also show on this figure three correlations for penetration given by Rogers ${ }^{2}$

\section{McDaniel and Graves ${ }^{8}$}

$$
z / D=3.87 J^{0.3}(x / D)^{0.143}
$$

and Gruber et $\mathrm{al}^{5}$.

$$
z / D=J^{0.344} \ln [2.077(x / D)+2.059]
$$

$$
z / D=1.23 J[(x / D+0.5) / J]^{0.344}
$$

Rogers' correlation obtained by gas sampling for $\mathrm{x} / \mathrm{D}<$ 120 is larger than the other two correlations. McDaniel and Graves based their correlation (for $\mathrm{X} / \mathrm{D}<20$ ) on 
LIF data, and Gruber et al. based their correlation on Mie scattering (for $x / D<8$ ). (Note that equation 13 is modified to account for the a different reference location than that used by Gruber et al.) As shown in figure 9, the penetration obtained from the Rayleigh scattering agrees reasonably well with the correlations of McDaniel and Graves and Gruber et al.

Other experimental comparisons include measurements using NO PLIF (Mach 1.4, J = 2.1) presented by Lee et al ${ }^{11}$ that show penetration values between Rogers, and McDaniel and Graves' correlations. Schlieren data (Mach 3.0, J = 1.7) by Papamoschou and Hubbard ${ }^{13}$ show similar penetration at $x / D=6$. As shown on figure 9 , the penetration measurements obtained from our shadowgraphs are somewhat larger than those obtained from Rayleigh scattering. Our penetration values obtained from Rayleigh scattering agree best with and McDaniel and Graves' equation 12. Both sets of data show that the helium plume does not mix very quickly with the main tunnel flow. Also, the spreading of the helium transverse to the flow direction is greater than the penetration into the flow. Note that this effect is larger than it appears in the Rayleigh scattering images because of the oblique viewing angle. Wall static pressure data obtained with helium injection through the roof and floor are shown in figure 10. The roof data denoted with a $\star$ may be slightly high due to a drift in the pressure measurement system. Both static pressure data show a rise in the vicinity of the injector, followed by a decrease below the tunnel static pressure just downstream of the injector. The pressure returns to the tunnel mainstream value about 4 nozzles downstream of the injector. This is in general agreement with data presented by Zukoski and Spaid ${ }^{12}$.

\section{Concluding remarks}

This preliminary work demonstrated the feasibility of using filtered Rayleigh scattering to measure helium mole fraction and depth of gaseous helium penetration into a Mach 3 flow. The expected uncertainty in the mole fraction based on photon shot noise was on the order of 0.2 for a 10 shot average. However, the actual uncertainty was larger because of Mie scattering from particles in the tunnel and injectant flows.

A number of changes are planned to improve the data quality. A large capacity helium supply is being installed. This will allow much more efficient use of test run time compared to the use of 220 scf cylinders used in this work. Also, this allows study of larger momentum flux ratios for future injection design development. Better quality windows are being procured for future tests. These windows will be fused silica or BK7 and will have much better surface quality than the windows used in these tests. This should result in a significant reduction in the amount of stray scattered laser light. In addition, these new windows will be mounted such that they can quickly be removed for cleaning. (The windows used in this work require a full day to remove and replace.) The problem of Mie scattering from particles will be reduced with the installation of new filters in both the main tunnel flow air supply and in the injectant gas supply. (The injectant was not filtered in this work.) Effort will be made to reduce the stray laser light oy trmoroved baffling and by coating critical surfacs sket reffecting and/or absorbing black paint. The optics will be aligned according to the Scheimpflug condition so particle images will be in focus and can more easily be removed from the Raykex

The effectiveness of the iouine absorption filter is limited with the pulsed NdYAG laser used for this work. This is likely a result of weak lasing in a mode other than the mode matched to the injection seeder. Use of a CW laser (such as an argon-ion laser) with better spectral properties will be considered if the particle loading can be sufficiently reduced.

Mole fraction measurement from single-shot images will be obtained using CCD binning to increase the signal-to-noise ratio. This would give instantaneous planar data on the mixing (but with a reduction in the spatial resolution).

The planned test program includes the study of a variety of injector designs including multiple inline arrays of round sonic and supersonic nozzles and new wedge-shaped injectors. These injectors will be located in the tunnel roof and floor modules, both downstream of the tunnel nozzle exit and later in the diverging section of the nozzle. Velocity measurements will also be obtained using a previously developed technique ${ }^{29}$ based on spectrally resolved Rayleigh scattering. Also, faster and more accurate control of tunnel operating conditions will be pursued with the implementation of artificial neural networks ${ }^{30}$.

\section{Acknowledgments}

We would like to acknowledge the efforts of $\mathrm{Mr}$. W. Trevor John and Mr. Bertram Floyd, who were responsible for setting up and aligning the Rayleigh scattering optical system used for this work, Mr. Richard Senyitko and Mr. Salvatore Giordano, who were responsible for the wind tunnel preparation, and Mr. Kenneth Weiland, who was responsible for setting up the shadowgraph system. Also, we thank Dr. Joseph Forkey for providing us with his iodine absorption code. 


\section{References}

${ }^{1}$ Borowski, S.K. and Cassenti, B.N., "Nuclear Thermal Propulsion", Aerospace America, December 1995, p. 49.

${ }^{2}$ Rogers,R.C., "A Study of the mixing of hydrogen injected normal to a supersonic airstream", NASA TN D6114, 1971.

${ }^{3}$ Fuller, E.J., Mays, R.B., Thomas, R.H., and Schetz, J.A.," "Mixing Studies of Helium in Air at High Supersonic Speeds", AIAA Journal, Vol. 30, No. 9, 1992, pp. 2234-2243.

${ }^{4}$ Hermanson, J.C., and Winter, M., "Mie Scattering Imaging of a Transverse, Sonic Jet in Supersonic Flow", AIAA Journal, Vol. 31, No. 1, 1993, pp. 129-132.

${ }^{5}$ Gruber, M.R., Nejad, A.S., Chen, T.H., and Dutton, J.C., "Mixing and Penetration Studies of Sonic Jets in a Mach 2 Freestream", Journal of Propulsion and Power, Vol. 11, No. 2,1995 , pp. 315-323.

${ }^{6}$ Island, T.C., Patrie, B.J., Mungal, M.G., and Hanson, R.K., "Instantaneous Three-Dimensional Flow Visualization of a Supersonic Mixing Layer", Experiments in Fluids, Vol. 20, 1996, pp. 249-256.

${ }^{7}$ Escoda, M.C., and Long, M.B., "Rayleigh Scattering Measurements of the Gas Concentration Field in Turbulent Jets", AIAA Journal, Vol. 21, No. 1, 1983, pp. 81-84.

${ }^{8}$ McDaniel, J.C., and Graves, J., Jr., "Laser-InducedFluorescence Visualization of Transverse Injection in a Nonreacting Supersonic Combustor", Journal of Propulsion and Power, Vol. 4, No. 6, 1988, pp. 591-597.

${ }^{9}$ Hollo, S.D., McDaniel, J.C., and Hartfield, R.J. Jr., "Characterization of Supersonic Mixing in a Nonreacting Mach 2 Combustor", AIAA 30th Aerospace Sciences Meeting, Reno, NV, AIAA paper 92-0093, 1992.

${ }^{10}$ Wang, K.C., Smith, O.I., and Karagozian, A.R., "InFlight Imaging of Transverse Gas Jets Injected into Compressible Crossflows", AIAA Journal, Vol. 33, No. 12, 1995, pp. 2259-2263.

${ }_{11}$ Lee, M.P., McMillin, B.K., Palmer, J.L., and Hanson, R.K., "Planar Fluorescence Imaging of a Transverse Jet in a Supersonic Crossflow", Journal of Propulsion and Power, Vol. 8, No. 4, 1992, pp. 729-735.

${ }^{12}$ Zukoski, E.E., and Spaid, F.W., "Secondary Injection of Gases into a Supersonic Flow", AIAA Journal, Vol. 2, No. 10, 1964, pp. 1689-1696.

${ }^{13}$ Papamoschou, D, and Hubbard, D.G., "Visual Observations of Supersonic Transverse Jets", Experiments in Fluids, Vol. 14, 1993, pp. 468-476.

${ }^{14}$ McCann, G.J., and Bowersox, R.D.W., "Experimental Investigation of Supersonic Gaseous Injection into a Supersonic Freestream", AIAA Journal, Vol. 34, No. 2, 1996, pp. 317-322.

${ }^{15}$ Schetz, J.A., and Billig, F.S., "Penetration of Gaseous Jets Injected into a Supersonic Stream", Journal of Spacecraft, Vol. 3, No. 11, 1966, pp. 1658-1665.

${ }^{16}$ Fuller, E.J., Mays, R.B., Thomas, R.H., and Schetz, J.A., "Mixing Studies of Helium at High Supersonic Speeds", AIAA Journal, Vol. 30. No. 9, 1992, pp. 2234-2243.

${ }^{17}$ deGroot, W.A., Latham, R., Jagoda, J.I., Strahle, W.C., "Rayleigh Measurements of Species Concentration in a Complex Turbulent Flow", AlAA Journal, Vol. 25, No. 8, 1987, pp. 1142-1144.
${ }^{18}$ Everson, R., Manin, D., Sirovich, L., and Winter, M., "Quantification of Mixing Rate from Experimental Observations", AIAA 33th Aerospace Sciences Meeting, Reno, NV, AIAA paper 95-0169, 1995.

${ }^{19}$ Graham, S.C., Grant, A.J., and Jones, J.M., "Transient Molecular Concentration Measurements in Turbulent Flows Using Rayleigh Light Scattering", AlAA Journal, Vol. 12, No. 8, 1974, pp. 1140-1142.

${ }^{20}$ Goix, P.J., Leonard, K.R., Talbot, L., and Chen, J.Y., "Direct Measurement of Mixture Fraction in Reacting Flow using Rayleigh Scattering", Experiments in Fluids, Vol. 15, 1993, pp. 247-254.

${ }^{21}$ Stepowski, D. and Cabot, G., "Single-Shot

Temperature and Mixture Fraction Profiles by Rayleigh Scattering in the Development Zone of a Turbulent Diffusion Flame", Combustion and Flame, Vol. 88, 1992, pp. 296-308.

${ }^{22}$ Long, M.B., Levin, P.S., and Fourguette, D.C., "Simultaneous Two-Dimensional Mapping of Species Concentration and Temperature in Turbuient Flames", Optics Letters, Vol. 10, No. 6, 1985, pp. 267-269.

${ }^{23}$ Dyer, T.M., "Rayleigh Scattering Measurements of Time-Resolved Concentration in a Turbulent Propane Jet", AIAA Journal, Vol. 17, No. 8, 1979, pp. 912-914.

${ }^{24}$ Miles, R., and Lempert, W., "Flow Diagnostics in Unseeded Air", AIAA 28th Aerospace Sciences Meeting, Reno, NV, AIAA paper 90-0624, 1990.

${ }^{25}$ Forkey, J.N., Finkelstein, N.D., Lempert, W.R. \& Miles, R.B., "Demonstration and Characterization of Filtered Rayleigh Scattering for Planar Velocity Measurements", AlAA Journal, Vol. 34, No. 3, 1996, pp. 442-448.

${ }^{26}$ Forkey, J.N., "Development and Demonstration of Filtered Rayleigh Scattering - A Laser Based Flow Diagnostic for Planar Measurement of Velocity, Temperature and Pressure", Ph.D. dissertation \#2067-T, Princeton University, 1996.

${ }^{27}$ Hoffman, D., Münch, K.-U., and Leipertz, A., "TwoDimensional Temperature Determination in Sooting Flames by Filtered Rayleigh Scattering", Optics Letters, Vol. 21, No. 7, 1996, pp. 525-527.

${ }^{28}$ Kingslake, R., Optical System Design, Academic Press, New York, 1983, pp. 265-272.

${ }^{29}$ Seasholtz, R.G., Buggele, A.E., \& Reeder, M.F., "Instantaneous Flow Measurements in a Supersonic Wind Tunnel Using Spectrally Resolved Rayleigh Scattering", SPIE International Symposium on Optical Science, Engineering, and Instrumentation, San Diego, CA, July 9-14, 1995.

${ }^{30}$ Decker, A.J., and Buggele, A.E., "Automation of Some Operations of a Wind Tunnel Using Artificial Neural Networks", AlAA Journal, Vol. 34, No. 2, 1996, pp. 421-423. 


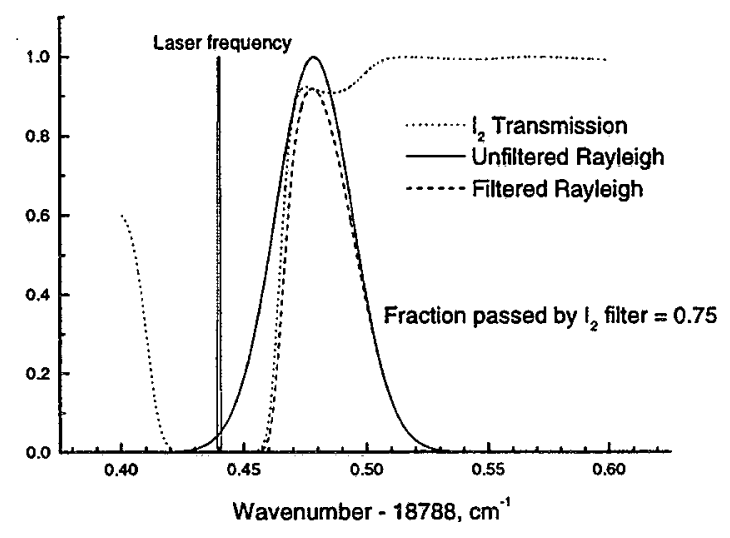

Fig. 1. Rayleigh scattered light transmitted through iodine cell, $\mathrm{p}=0.46 \mathrm{~T}$, cell length $=200 \mathrm{~mm}$., Mach 3 flow, laser wavenumber $=18788.44 \mathrm{~cm}^{-1}$

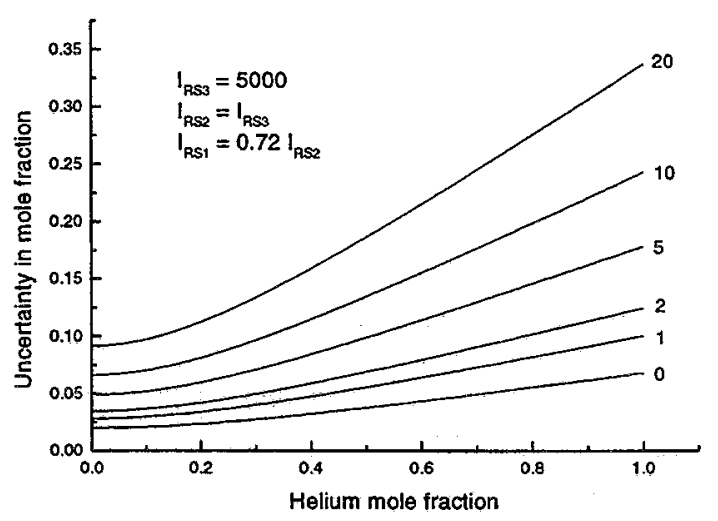

Fig. 2. Uncertainty in helium mole fraction as a function of mole fraction; parameter is ratio of background photoelectrons to Rayleigh scattering photoelectrons.

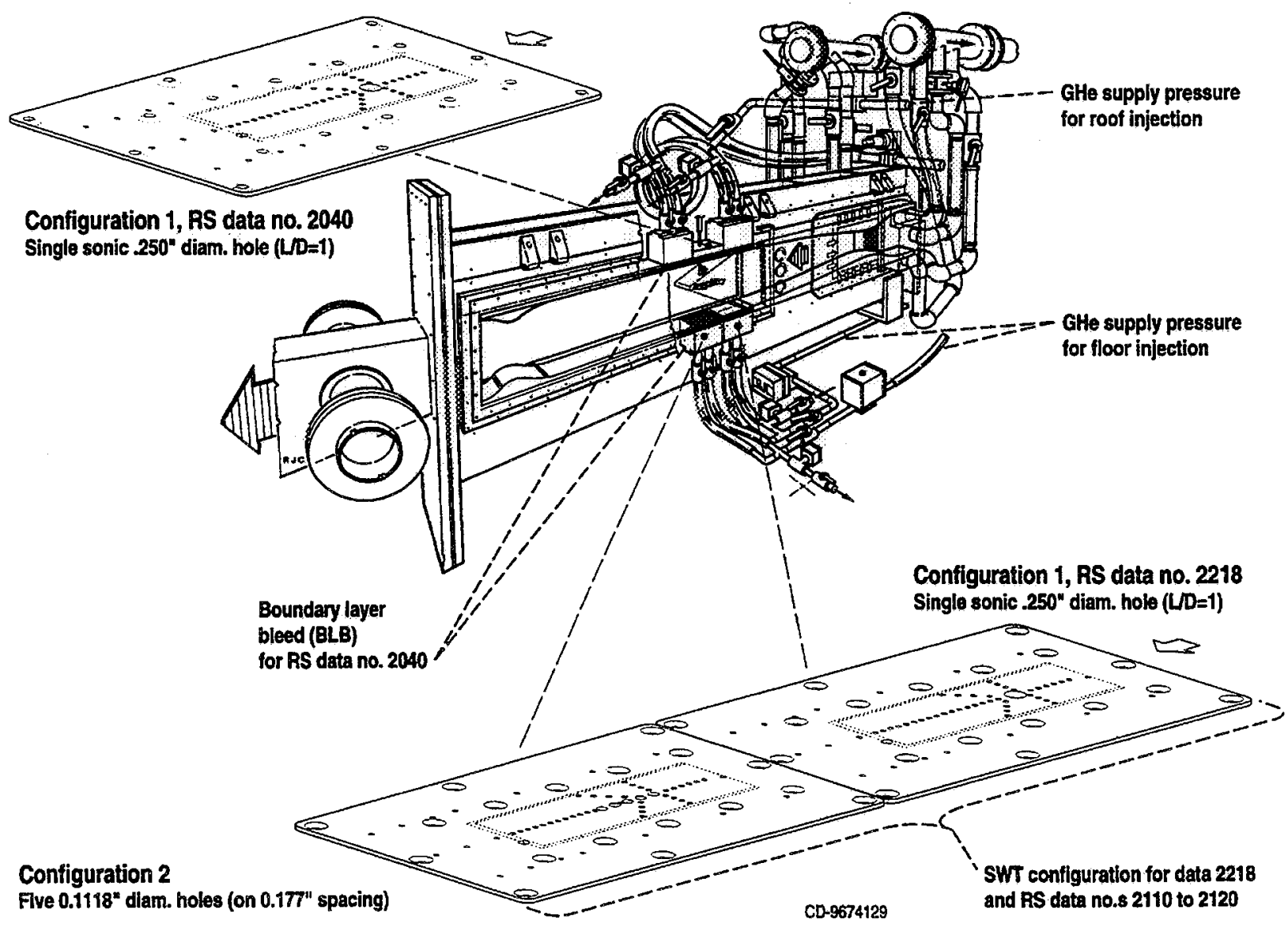

Fig. 3. Supersonic wind tunnel with boundary layer bleed; injector panel configurations used for Rayleigh scattering and shadowgraph tests shown. 
(a)
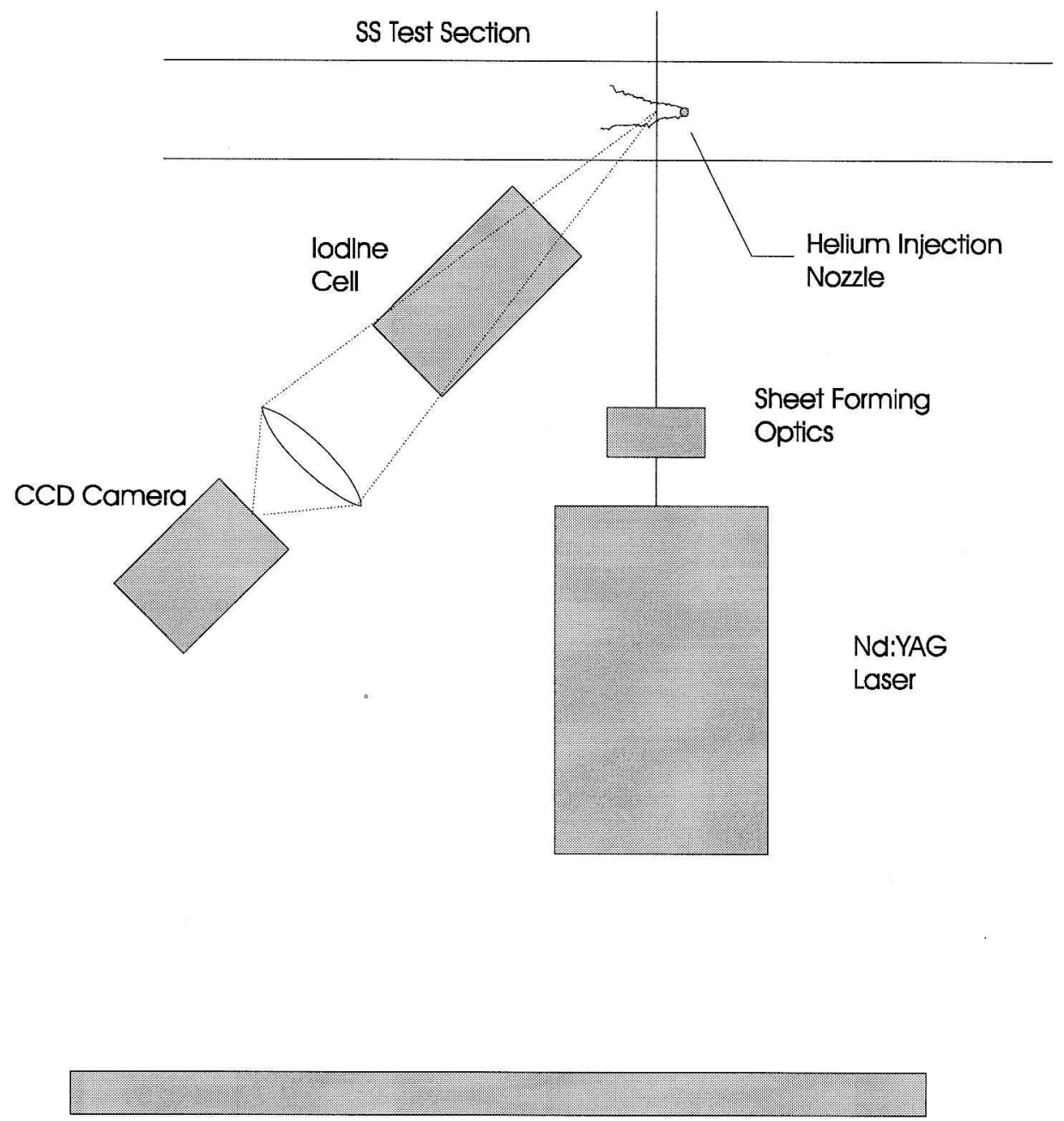

(b)

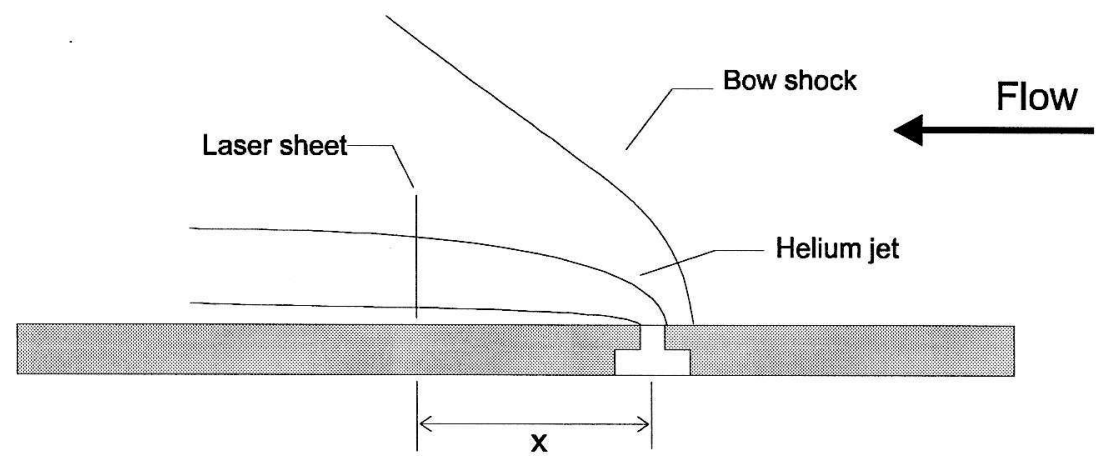

Fig. 4. (a) Optical setup for Rayleigh scattering measurements. (b) Side view of injection of helium through sonic nozzle into supersonic air flow. 


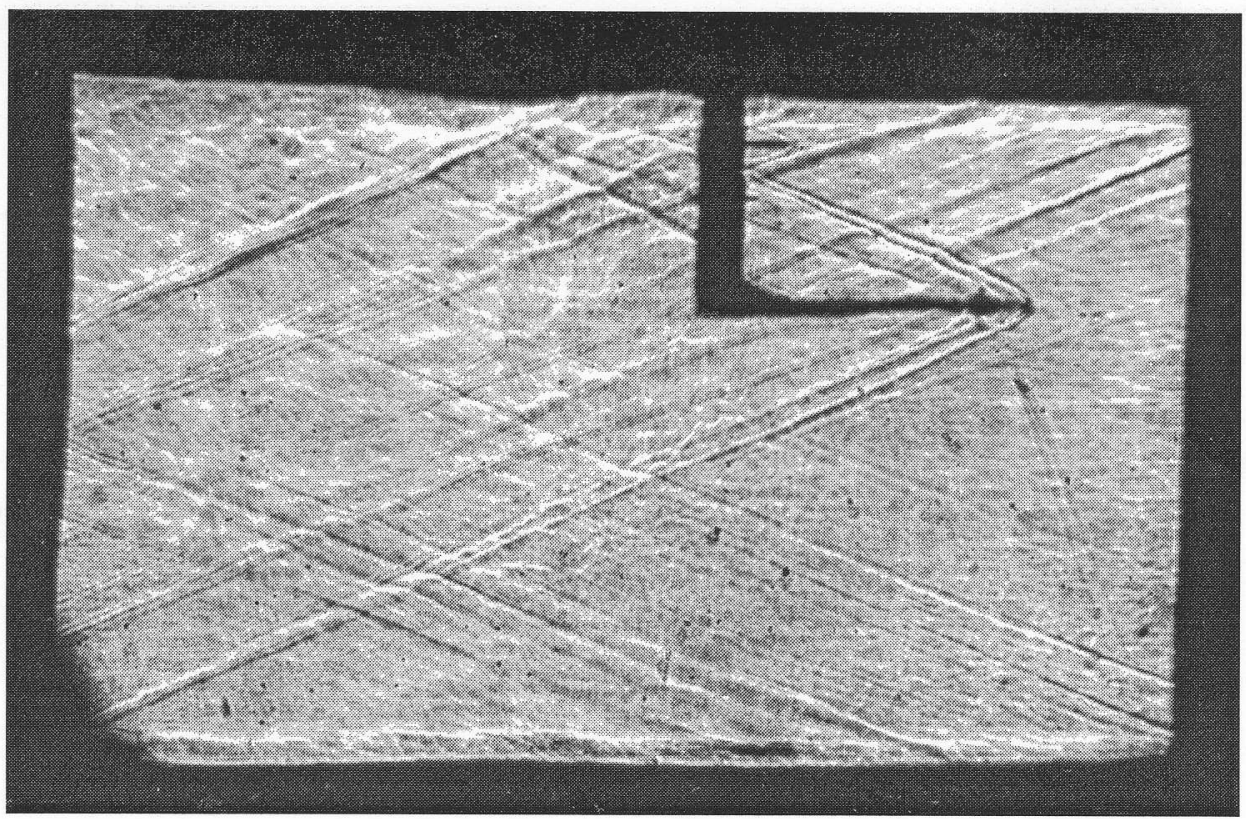

(a)

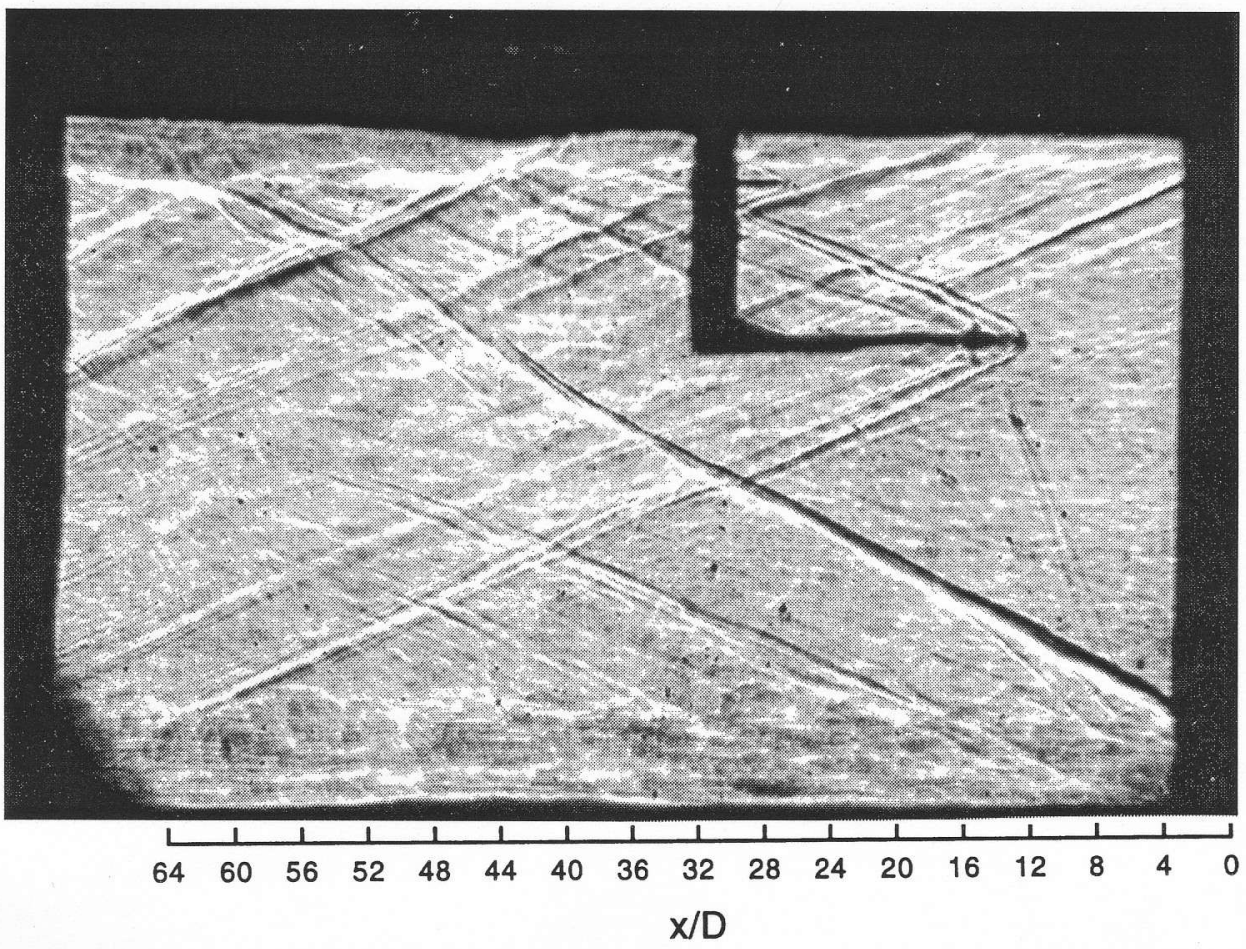

Fig. 5. Shadowgraphs: (a) is RDG 2217; Mach 3 flow without helium injection showing floor boundary layer, (b) is RDG 2218; Mach 3 flow with helium injection through floor module. 


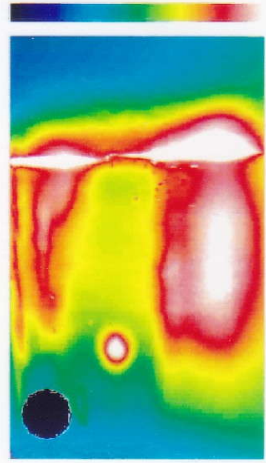

(a)

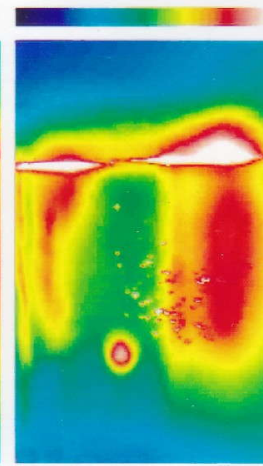

(b)

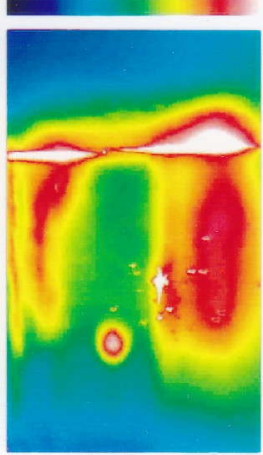

(c)

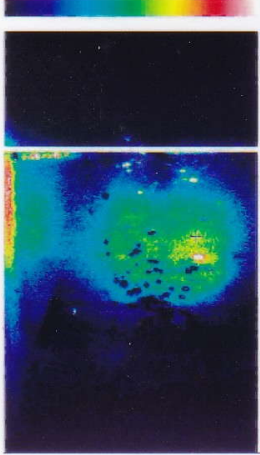

(d)

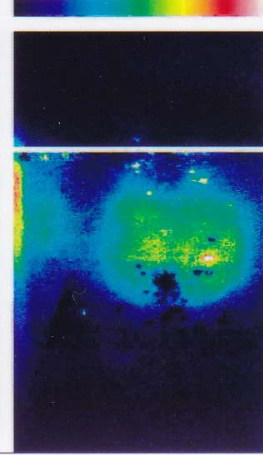

(e)

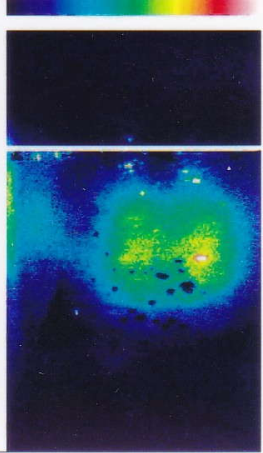

(f)

Fig. 6. (a) is raw image without helium injection; black circle is 1 nozzle diameter (b) and (c) are raw images with injection; (d-f) are difference images with injection image subtracted from image without injection; white line is tunnel roof (RDG 2040).
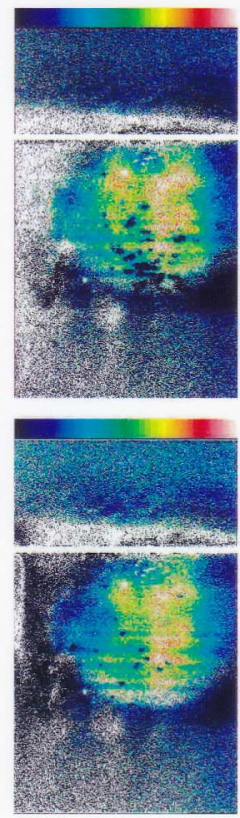
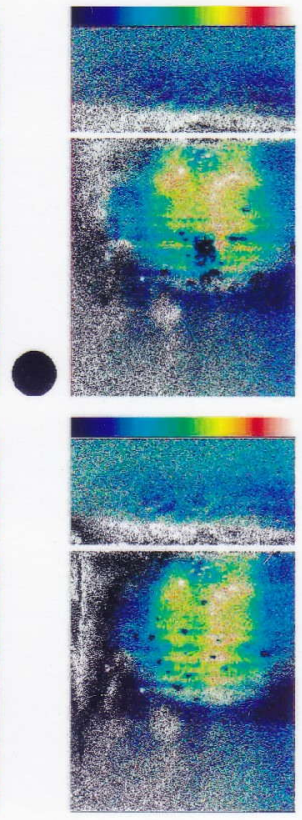
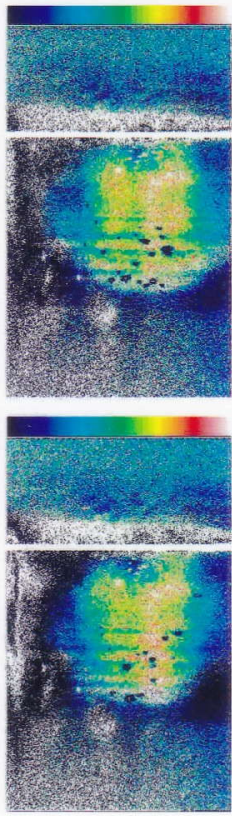
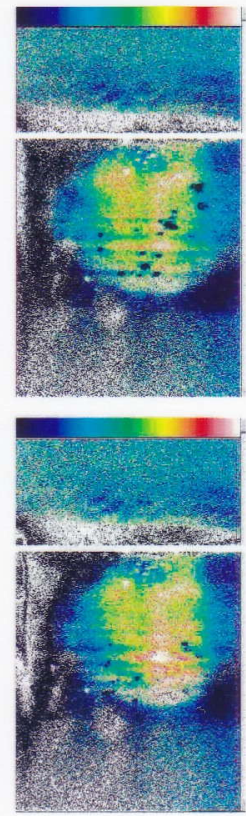

Fig. 7. Helium mole fraction; scale is 0 to 1 mole fraction; all images are 321 pixels wide by 532 pixels high; black circle is 1 nozzle diameter (RDG 2040)

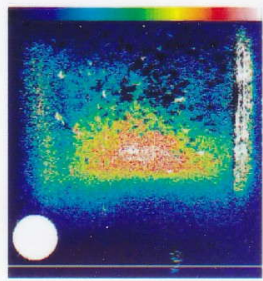

$\mathrm{x} / \mathrm{D}=4$

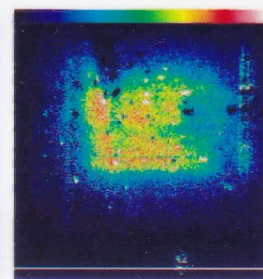

8

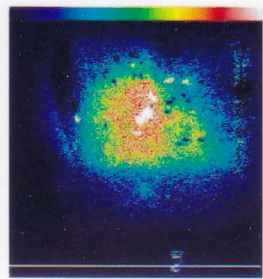

12

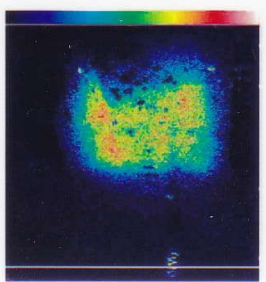

16

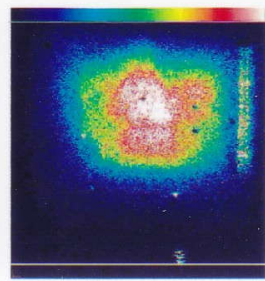

20

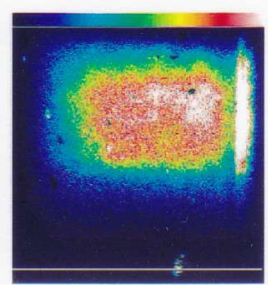

24

Fig 8. Difference images with injection image subtracted from image without injection; $x / D$ is distance downstream of leading edge of injection nozzle; white line is location of tunnel floor; white circle is 1 nozzle diameter; all images are 356 pixels wide by 362 pixels high; (RDG 2110-2118). 


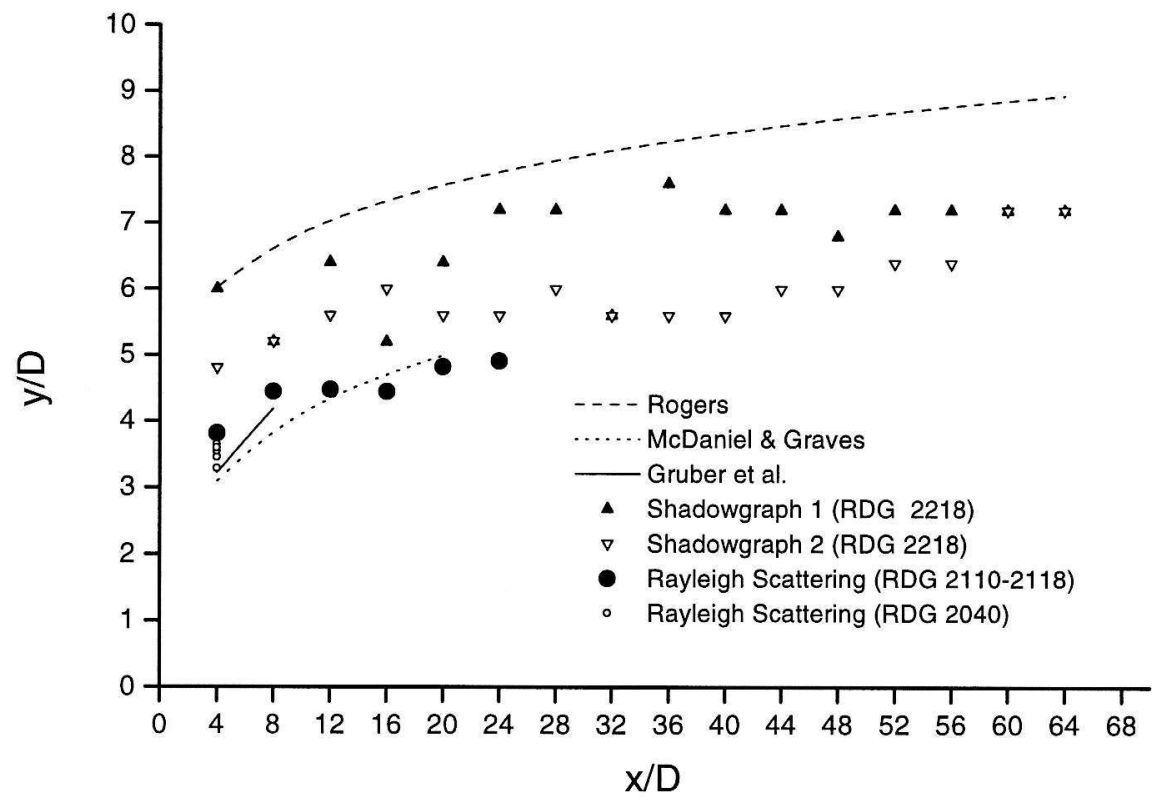

Fig. 9. Helium penetration determined from Rayleigh scattering and two single-shot shadowgraphs as a function of distance downstream of leading edge of injector. Also shown are correlations from Rogers (ref. 2), McDaniel and Graves (ref. 8), and Gruber et al. (ref. 5).

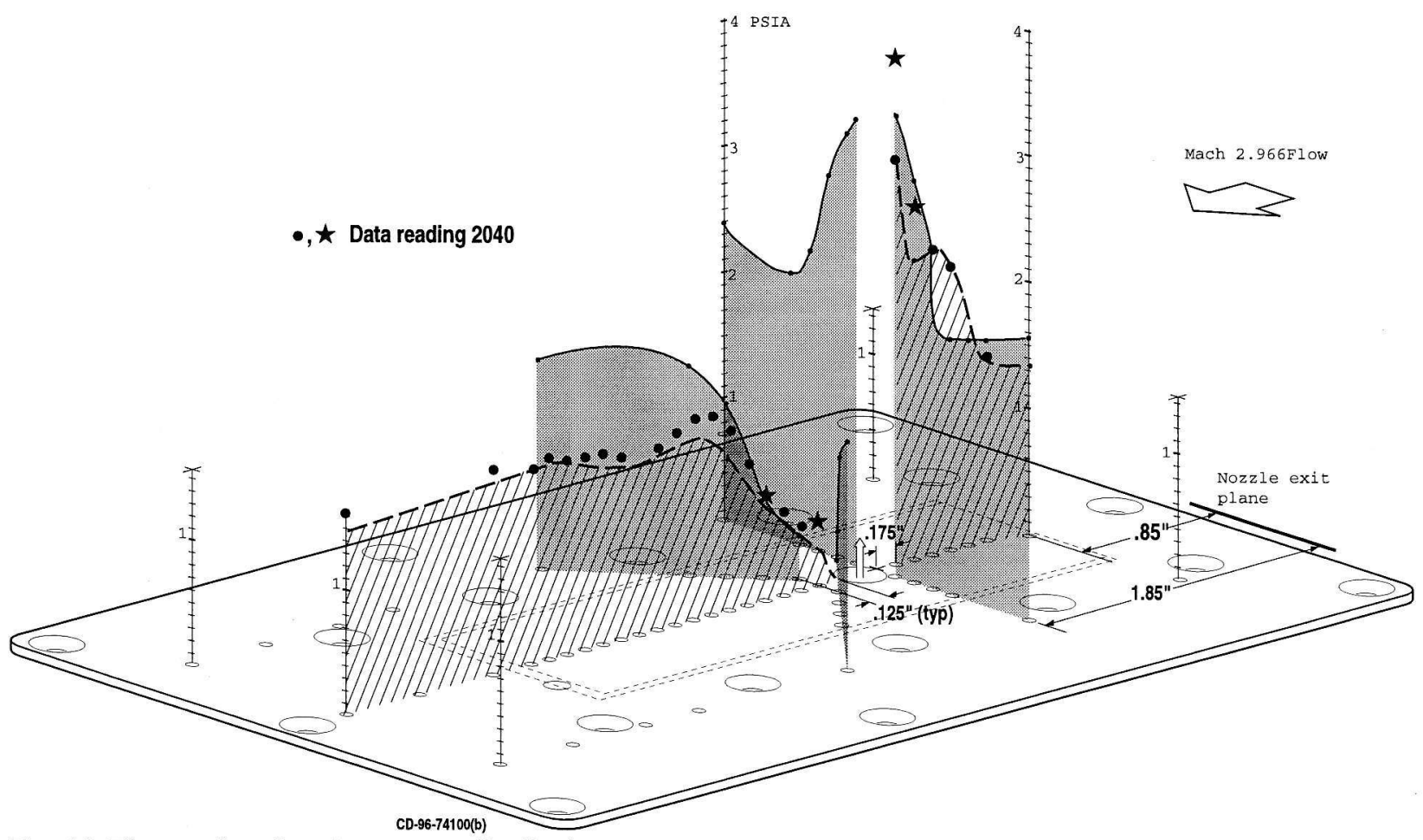

Fig. 10. Floor and roof static pressure distribution measurements for two Rayleigh scattering tests; RDG 2218 (shaded line); RDG 2040 roof pressure measurements indicated by $\bullet$ and $\star$ are shown for comparison purposes. 
Public reponing burden for this collection of intormation is estimated to average 1 hour per response, including the time for reviewing instructions, searching existing data sources, gathering and maintaining the data neөded, and completing and reviewing the collection of information. Send comments regarding this burden estimate or any other aspect of this galhe at intermation, including suggestions for reducing this burden, to Washington Headquarters Services, Directorate for Information Operations and Reports, 1215 Jefferson Davis Highway, Suite 1204, Arlington, VA 22202-4302, and to the Office of Management and Budget, Paperwork Reduction Project (0704-0188), Washington, DC 20503.

\begin{tabular}{|l|l|l|}
\hline 1. AGENCY USE ONLY (Leave blank) & $\begin{array}{c}\text { 2. REPORT DATE } \\
\text { January } 1997\end{array}$ & $\begin{array}{r}\text { 3. AEPORT TYPE AND DATES COVERED } \\
\text { Technical Memorandum }\end{array}$ \\
\hline
\end{tabular}

\section{TITLE AND SUBTITLE}

5. FUNDING NUMBERS

Study of Injection of Helium Into Supersonic Air Flow Using Rayleigh Scattering

6. AUTHOR(S)

WU-519-20-53

Richard G. Seasholtz and Alvin E. Buggele

7. PERFoRMING ORGANIZATION NAME(S) AND ADdRESS(ES)

National Aeronautics and Space Administration

Lewis Research Center

Cleveland, Ohio 44135-3191

8. PERFORMING ORGANIZATION

REPORT NUMBER

$E-10627$
9. SPONSORING/MONITORING AGENCY NAME(S) AND ADDRESS(ES)

National Aeronautics and Space Administration

Washington, DC 20546-0001
10. SPONSORING/MONITORING AGENCY REPORT NUMBEP

NASA TM-107409

AIAA-97-0155

\section{SUPPLEMENTARY NOTES}

Prepared for the 35th Aerospace Sciences Meeting \& Exhibit sponsored by the American Institute of Aeronautics and Astronautics, Reno, Nevada, January 6-10, 1997. Responsible person, Richard G. Seasholtz, organization code 5520, (216) 433-3754.

12a. DISTRIBUTIONAVAILABILITY STATEMENT

Unclassified - Unlimited

Subject Category 35

This publication is available from the NASA Center for AeroSpace Information, (301) 621-0390.

13. ABSTRACT (Maximum 200 words)

A study of the transverse injection of helium into a Mach 3 crossflow is presented. Filtered Rayleigh scattering is used to measure penetration and helium mole fraction in the mixing region. The method is based on planar molecular Rayleigh scattering using an injection-seeded, frequency-doubled Nd:YAG pulsed laser and a cooled CCD camera. The scattered light is filtered with an iodine absorption cell to suppress stray laser light. Preliminary data are presented for helium mole fraction and penetration. Flow visualization images obtained with a shadowgraph and wall static pressure data in the vicinity of the injection are also presented.

\begin{tabular}{|c|c|c|}
\hline \multicolumn{3}{|c|}{$\begin{array}{l}\text { 14. SUBJECT TERMS } \\
\text { Ravleigh scattering. Sunersonic flow }\end{array}$} \\
\hline $\begin{array}{l}\text { 17. SECURTY CLASSIFICATION } \\
\text { OF REPORT } \\
\text { Unclassified }\end{array}$ & $\begin{array}{l}\text { 18. SECURITY CLASSIFICATION } \\
\text { OF THIS PAGE } \\
\text { Unclassified }\end{array}$ & $\begin{array}{l}\text { 19. SECURITY CLASSIFICATION } \\
\text { OF ABSTRACT } \\
\text { Unclassified }\end{array}$ \\
\hline
\end{tabular}

15. NUMBER OF PAGES 14

16. PRICE CODE

$\mathrm{A03}$

20. LIMTTATION OF ABSTRACT

Standard Form 298 (Rev. 2-89) Prescribed by ANSI Std. Z39-18 298-102 
National Aeronautics and

Space Administration

Lewis Research Center

21000 Brookpark Rd.

Cleveland, $\mathrm{OH}$ 44135-3191

Official Business

Penalty for Private Use $\$ 300$

POSTMASTER: If Undeliverable - Do Not Relurn 